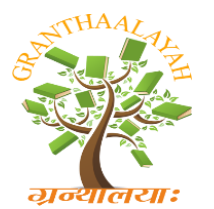

INTERNATIONAL JOURNAL OF RESEARCH GRANTHAALAYAH

A knowledge Repository

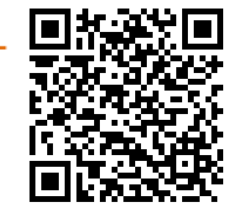

Management

\title{
EVALUATION OF CORPORATE DIGITAL ANNUAL REPORTING
}

\author{
Harpreet Singh Walia *1 \\ ${ }^{* 1}$ Sikh National College, Banga, INDIA
}

\begin{abstract}
Corporate reporting process has undergone a complete makeover in the recent times. It has affected companies and stakeholders in the most positive way as ever. Emergence of digital annual reporting is also one of the paramount changes that is slowly taking the place of old traditional printed annual reports. Nowadays many companies are using digital annual reporting as an effective medium to distribute its annual reports to the stakeholders. Digital annual reporting use the electronic coupled with internet medium for fast and cost-effective corporate reporting. The benefits are much more than the cost of this new generation method. Hence now many companies understand the significance of digital annual reporting and are trying to embed the medium as an essential part of their reporting practices. But this medium is also not free from defects and shortcomings. In this article a brief evaluation of digital annual reporting is being done to find out the various benefits and limitations of using digital annual reporting by the corporate companies.
\end{abstract}

Keywords:

Digital annual reporting, digital reports evaluation, electronic reporting.

Cite This Article: Harpreet Singh Walia, "EVALUATION OF CORPORATE DIGITAL ANNUAL REPORTING" International Journal of Research - Granthaalayah, Vol. 4, No. 2 (2016): 179-183.

\section{INTRODUCTION}

Annual reports are aimed to give stakeholders and other interested persons information about the company's activities and financial performance. In the past the companies have only one option if they want to distribute information about their performance and that is to prepare annual reports. But due to advancement in internet technology and awareness about the benefits of web, many companies have resorted to Digital Annual reporting. It is due to the fact that in recent times the traditional annual report seems to be dull and overloaded with information containing lots of figures. Digital Reporting is the need of present generation of companies and stakeholders. Today is the generation of internet when most of the companies have created their websites and majority of the shareholders are using internet, it is necessary to provide reports in digital or electronic form in addition to the traditional annual report. So, in recent times most of the companies have adopted digital annual reports as a medium of distributing their information 
along with presenting reports in traditional printed format. The digital reports are uploaded by the companies on their websites and any interested person can download and view these reports by visiting the companies' website. It is in the initial stage of development but it has huge potential.

\section{OBJECTIVE OF THE STUDY}

The objective of the study is to evaluate digital annual reporting by studying its benefits and problems to the corporate sector.

\section{DISCUSSION}

The evaluation of using digital annual reporting by the corporate sector can be discussed by studying the two aspects i.e. Benefits of digital annual reporting and Limitations of digital annual reporting.

\section{BENEFITS OF DIGITAL ANNUAL REPORTING}

Nowadays many companies are using various formats to create digital annual reports. These companies are using mixture of various interactive features like audio, video, animations, images etc. in their digital annual reports to make them more interesting and useful to the users. There are various advantages of digital annual reporting:

Not Expensive: Digital reporting is not expensive at all. Any company can create website and upload their digital reports on it. Unlike printed reporting method there is no need to spend huge expenditure on paper and publishing of printed reports.

Easily accessible: Electronic report is easily accessible by the stakeholders as compared to the printed reports. These reports are easily available on the website of company and can be downloaded by visiting at that website. Unlike printed reports which mean that company has to physically mail its copy to each interested person individually, digital reports are within the reach of everyone.

Interactive Content: Digital Reports allow the company to make their information interactive by adding variety of multimedia content like audio, video, images and animations etc. in their annual reports. It helps in making the reports of companies interesting and useful for the users.

Easy to update : Printed reports have a very short life and if any change has to be made in these reports, then it takes many days or even months to update information and then re-publish them again. But in case of electronic reports, updating of information is very easy and quick

Two-way interaction: Digital reports provide an opportunity to company to have two-way interaction with the stakeholders. There is always a feedback option on website of every company through which the stakeholder can interact with the company. It is an effective way to communicate with stakeholders and potential investors. 
Round the clock availability: The information is loaded on the website of the company and it runs 24 hrs. \& 365 days a year. So investors can view the information at anytime from anywhere in the world.

Time saver: The information on website of companies can be easily assessable. One just needs an internet connection, Laptop or PC and knowledge about the web address of the company website. It saves a lot of time of the investor.

Global reach: Electronic reports are uploaded by companies on their websites. These websites can be easily accessed and reports can be viewed or downloaded free of cost by any user. So, it provides unrestricted global access and increase the potential audience of the company. Any person who wants to view or read any information about the company can do it with a single click of his computer mouse, sitting at home.

Unlimited space: Companies can add unlimited amount of information on their websites. There is no space constraint on the web medium. Unlike printed reports which have high cost with limited space, the companies can add as much information as possible in digital reports. Archived information such as annual reports for multiple years can be displayed on websites.

Better monitoring by regulators: The digital reports posted by the companies on the websites allow the regulators to better monitor and control the activities of the corporations. The information is available on variety of formats and it can be effectively used for analysis.

\section{PROBLEMS/CHALLENGES/DISADVANTAGES OF DIGITAL REPORTING}

No doubt there are various advantages of corporate reporting through web for companies and stakeholders. But there are certain problems of digital reporting which stand like hurdles between the smooth processes of corporate reporting through web. These are as follows:

Security issues: Digital reports with full information cannot be compared to the printed reports because of various security and authenticity issues. Printed reports contain signature of auditors which serve as guarantee for the integrity and authenticity of the information. But this thing is found absent in the electronic documents. So the authenticity of electronic reports cannot be verified.

Lack of Uniform presentation of information on web: Companies differ in their practices in publishing digital reports. This drawback leads to reducing the usefulness of data for comparison purposes. A user cannot compare information of companies due to lack of proper standard for publishing web-based information.

Lack of adequate content in digital reports: Sometimes reports available on the websites contain less information than the printed reports which is of less or no use to investors for making rational decisions. This is a big problem as it has a bearing on the decision of the stakeholders. 
Lack of suitable formats: No doubt many companies are uploading their reports on their websites in the format of HTML and PDF. But these two formats do not provide the facility of automatic analysis of information by the investors. This problem can be solved if all the companies adopt new and advanced technology like XBRL.

Website maintenance Costs: Many companies are now using websites to distribute digital reports. It offers various benefits but the website need regular maintenance and updating on periodical basis. Maintaining the websites is not an easy task, various technical experts and computer professionals are needed for keeping website updated. They need to be paid for their services.

Crashing of websites: Sometimes due any technical error, a company website may be crashed that will make temporary or permanent damage to the digital report available on the internet. In some cases the reports may be lost forever.

Large size of Reports: Companies upload various type of information on their websites. In many situations users face lot of problems in downloading the digital reports from the websites due to their large size and slow internet speed of the users. It waste lot of time and reduces the efficiency of the web-based medium.

Software issues: If a user wants to download any digital report from the website of the company, then he must have compatible software in the PC which will allow him to view and read that file.

Problem of viruses: The digital report saved on hard disk drive in PC by any user may become corrupted if it is attacked by any virus. This lead to partial or complete loss of information. Hence a user needs to be careful when saving the information. A back up may be created.

Requirement of internet: For uploading the digital reports as well as downloading them from the website, a person must have internet connection. Without the internet facility the communication of report is not possible from company to third parties.

\section{CONCLUSION}

To conclude it can be said that digital annual reporting is an interactive method for making annual reports more interesting and useful to users than the dull and unattractive printed reports. Many companies have understood the importance of digital reporting and have started distributing their reports in electronic form. It offers many benefits to the companies but it also have various attached to it. So companies must set up an effective control system to eliminate all the problems and shortcomings of using digital annual reporting.

\section{REFERENCES}

[1] A.K. Vashisht B.B. Tandon P.P. Arya, "Corporate Governance" Deep and Deep Publications.

[2] Bibhuti B. Pradhan, " Corporate reporting in a changing environment." 
[3] Claudette Guzan Artwick," Reporting and Producing for Digital Media (Media and Technology Series)."

[4] Geoff Everingham, Suresh Parbhoo Kana, "Corporate Reporting: 8th Edition" Pricewaterhousecoopers.

[5] Harpreet Singh Walia (2016), “Corporate e-reporting” Sharma Publications, 1st edition, Jalandhar.

[6] www.wikipedia.com.

[7] Mark Briggs," Journalism Next: A Practical Guide to Digital Reporting and Publishing."

[8] Megan Fromm," Digital Content Creation." 